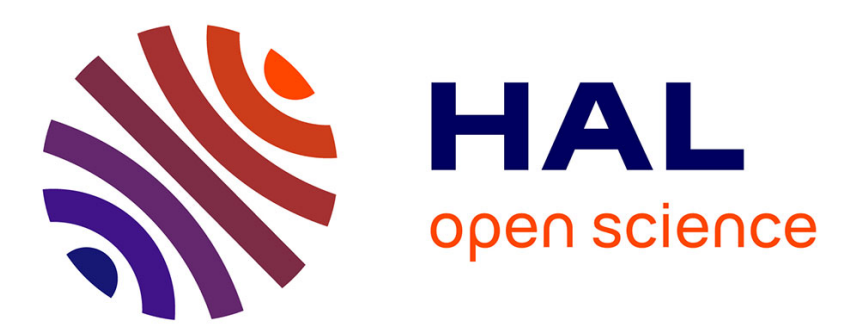

\title{
Micro-kinetic Generator: Modeling, Energy Conversion Optimization and Design Considerations
}

\author{
Marianne Lossec, Bernard Multon, Hamid Ben Ahmed
}

\section{To cite this version:}

Marianne Lossec, Bernard Multon, Hamid Ben Ahmed. Micro-kinetic Generator: Modeling, Energy Conversion Optimization and Design Considerations. MELECON 2010, Apr 2010, Valletta, Malta. pp.1516-1521. hal-00495674

\section{HAL Id: hal-00495674 https://hal.science/hal-00495674}

Submitted on 28 Jun 2010

HAL is a multi-disciplinary open access archive for the deposit and dissemination of scientific research documents, whether they are published or not. The documents may come from teaching and research institutions in France or abroad, or from public or private research centers.
L'archive ouverte pluridisciplinaire HAL, est destinée au dépôt et à la diffusion de documents scientifiques de niveau recherche, publiés ou non, émanant des établissements d'enseignement et de recherche français ou étrangers, des laboratoires publics ou privés. 


\title{
Micro-kinetic Generator: Modeling, Energy Conversion Optimization and Design Considerations
}

\author{
Marianne Lossec ${ }^{\# 1}$, Bernard Multon ${ }^{\# 2}$, Hamid Ben Ahmed ${ }^{\# 3}$ \\ " SATIE, ENS CACHAN Bretagne, CNRS, UEB, \\ Avenue Robert Schuman, F-35170 BRUZ \\ marianne. lossec@bretagne.ens-cachan.fr \\ bernard.multonebretagne. ens-cachan. fr \\ hamid.benahmedebretagne.ens-cachan.fr
}

\begin{abstract}
This article focuses on a micro-kinetic generator, which is used in Autoquartz watches designed by the Swiss manufacturer ETA (part of the Swatch Group). This original electromechanical system, incorporating an intermediate energy storage located in a spring, is based on harnessing the energy from movement. We have built an electromechanical model using the Matlab Simulink application and proceeded with its experimental validation on various movement profiles. Our research has highlighted the existence of an optimal transfer of energy (obtained by either influencing generator design or regulating output voltage of the active rectifier connected to the generator) that helps maximize energy recovery. Finally, this paper presents the results of a system resizing study for the purpose of studying potential system productivity at other scales, and highlights the existence of an optimal set of parameters maximizing energy recovery.
\end{abstract}

\section{INTRODUCTION}

Many portable, low-consumption electronic systems now make it possible to envisage self-supply from resources available in the environment. In this context, our laboratory has been working for several years on multi-source recovery energy systems, their energy potential and strategies for managing this energy $[1,2]$.

Concerning mechanical energy recovery, a wide range of devices that convert this energy resulting from vibrations and motion into electrical energy have already been identified and studied [3-5]. Such a conversion step can be performed by means of piezoelectric generators or a linear or rotating electromagnetic generator. This research is devoted to investigating a system that incorporates a rotating electromagnetic generator with intermediate energy storage in a spring, thus enabling energy recovery from very slow movements.

The Autoquartz watch works like a traditional quartz watch, with the particularity that it utilizes the movement of the watch wearer as an energy source. An oscillating weight transmits mechanical energy to a micro-generator and subsequently to an electrical accumulator via a spiral spring positioned within a micro barrel (Figs. 1 and 2).

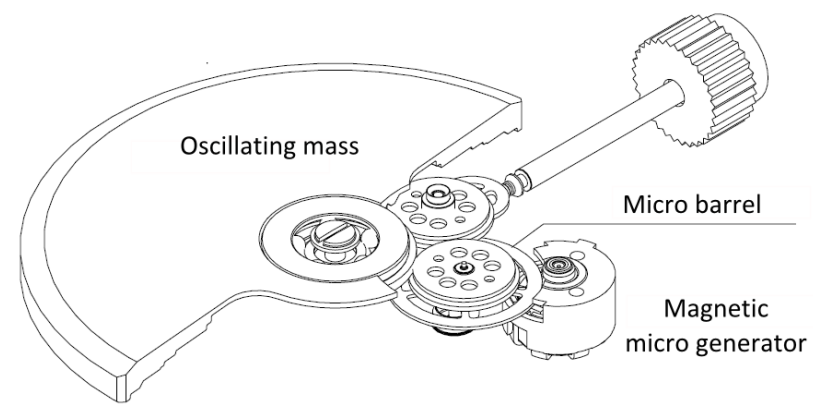

Fig. 1. 3D view [6] of the Autoquartz system

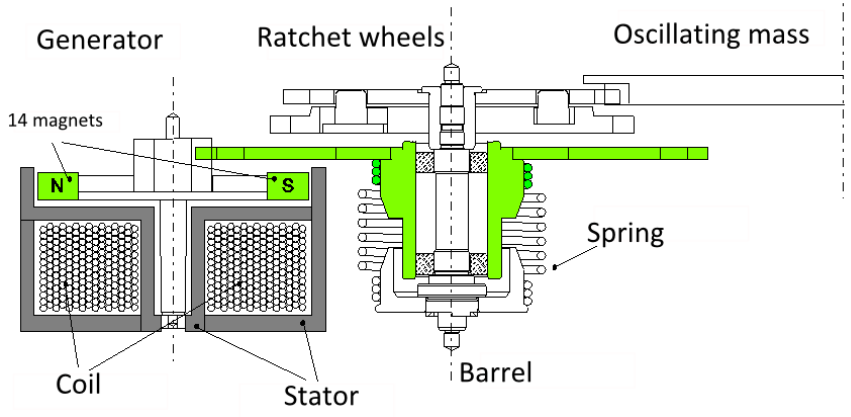

Fig. 2. Sectional view [7] of the Autoquartz system

The mechanical power supplied by the oscillating weight is distributed to two ratchet wheels, one of which has been fastened to the lower extremity of a spiral spring. The weight oscillation action is able to wind the spring (with a multiplication ratio $m_{1}$ equal to 1.6) regardless of movement direction or range. Once the spring torque exceeds the detent torque amplitude of the generator transmitted through a multiplier gear with a ratio $\mathrm{m}_{2}$ equal to 5 , the spring unwinds suddenly, resulting in a single-phase permanent magnet generator rotation (claw pole stator structure). Fig. 7 shows the electromotive force variation cycle, which highlights the change in speed during this cycle.

A high efficiency full-wave active synchronous rectifier (with MOSFET) convert the energy in order to charge an accumulator buffer (a supercapacitor or lithium element, depending on the watch model); like in traditional quartz watches, this step serves to redistribute energy to the electronic counting and stepper motor control electronics to ensure the watch hands are running smoothly. 
Some specifications of the Autoquartz system, useful for modeling purposes, are listed in the following table [8,9]. It will be seen further below that the identifications actually carried out lead to slightly different values:

TABLE I

INITIAL SPECIFICATIONS OF THE AUTOQUARTZ SYSTEM [8,9]

\begin{tabular}{|c|c|}
\hline Autoquartz system parameter & $\begin{array}{c}\text { Numerical } \\
\text { value }\end{array}$ \\
\hline External diameter of the system $\left(\mathrm{d}_{\mathrm{osc}}\right)$ & $26.6 \mathrm{~mm}$ \\
\hline Total system thickness $\left(\mathrm{th}_{\mathrm{osc}}\right)$ & $3.95 \mathrm{~mm}$ \\
\hline Moment of inertia of the weight $\left(\mathrm{J}_{\mathrm{osc}}\right)$ & $220 \mathrm{~g} \cdot \mathrm{mm}^{2}$ \\
\hline Weight/spring multiplication ratio $\left(\mathrm{m}_{1}\right)$ & $45: 28=1.6$ \\
\hline Spring stiffness $\left(\mathrm{k}_{\mathrm{sp}}\right)$ & $12.5 \mu \mathrm{Nm} / \mathrm{rad}$ \\
\hline Spring/generator multiplication ratio $\left(\mathrm{m}_{2}\right)$ & $60: 12=5$ \\
\hline Amplitude of the generator detent torque $\left(\mathrm{T}_{\mathrm{dMax}}\right)$ & 8 to $15 \mu \mathrm{Nm}$ \\
\hline Amplitude of the excitation flux $\left(\Phi_{\mathrm{fMax}}\right)$ & $0.6 \mathrm{mVs}$ \\
\hline Number of pole pairs $($ generator $)(\mathrm{p})$ & 7 \\
\hline Moment of inertia of the rotor $\left(\mathrm{J}_{\mathrm{G}}\right)$ & $0.03 \mathrm{~g} \cdot \mathrm{mm}^{2}$ \\
\hline Internal resistance of the armature $\left(\mathrm{R}_{\mathrm{G}}\right)$ & $320 \Omega$ \\
\hline ON resistance of the MOSFETs $\left(\mathrm{R}_{\mathrm{MOS}}\right)$ & $30 \Omega$ \\
\hline
\end{tabular}

\section{ELECTROMECHANICAL MODELING}

To establish a design and optimization tool for harnessing the energy from movement through the device Autoquartz, we have developed an energy productivity model that runs on Matlab-Simulink.

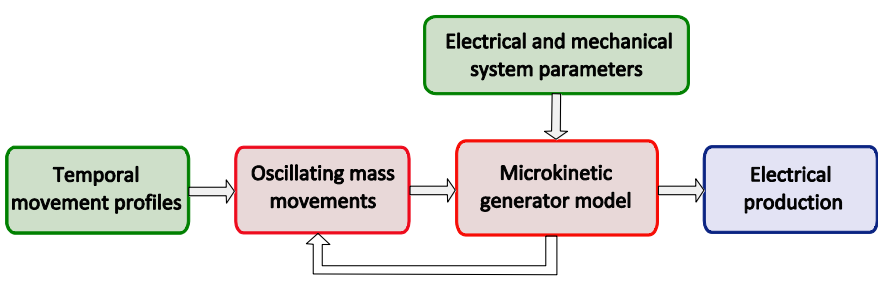

Fig. 3. Synoptic diagram of the micro-kinetic production model based on motion profiles

This model is based on the fundamental principle of dynamics applied to a solid rotation, which in our case is the generator rotor. Let's consider $\mathrm{T}_{\mathrm{G}}$ as the restoring torque transmitted by the spring through the speed multiplier, $T_{d}$ as the generator detent torque, $\mathrm{T}_{\mathrm{em}}$ the electromagnetic torque (proportional to discharge current $\mathrm{I}_{\mathrm{G}}$, and sinusoidal), and $\mathrm{T}_{\mathrm{f}}$ a viscous friction torque (intended to represent all types of friction and identified indirectly from experiment).

The angular difference between the two spring extremities, relative to spring stiffness $k_{s p}$, defines the restoring torque $T_{s p}$. Now, let's assume $\alpha_{\mathrm{osc}}$ and $\alpha_{\mathrm{G}}$ to be the angular positions of low and high spring extremities respectively; this torque can then be expressed by $T_{s p}=k_{s p}\left(\alpha_{o s c}-\alpha_{G}\right)$ and transmitted onto the rotor shaft through a gear train with a ratio equal to $\mathrm{m}_{2}$, as indicated above (the notation used here is $\mathrm{T}_{\mathrm{G}}$ ).

The electromagnetic micro-generator structure is nonconventional (Fig. 4): it consists of a claw pole stator structure of the kind found in magnet stepper motors. Also, it is singlephase with 7 pole pairs. The inductive effects are insignificant due to scale effects and will be neglected hereafter.

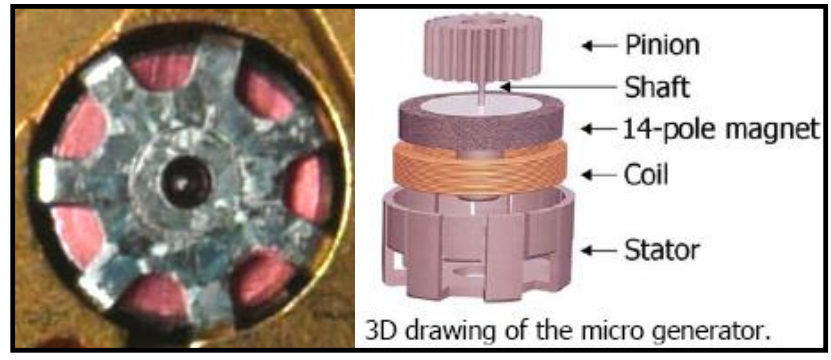

Fig. 4. Photography and 3D view of the micro-generator [9]

The micro-generator rotates when the restoring torque of the spring (due to mechanical tension produced by the combined weight rotations) is greater than the peak value $\mathrm{T}_{\mathrm{dMax}}$ of the detent torque. This latter torque (due solely to the interaction of permanent magnets with stator teeth) is dependent on the rotor angle $\theta_{\mathrm{G}}$. Fig. 5 illustrates, using conventional generator notation, the interaction between the restoring torque of the spring and this detent torque.

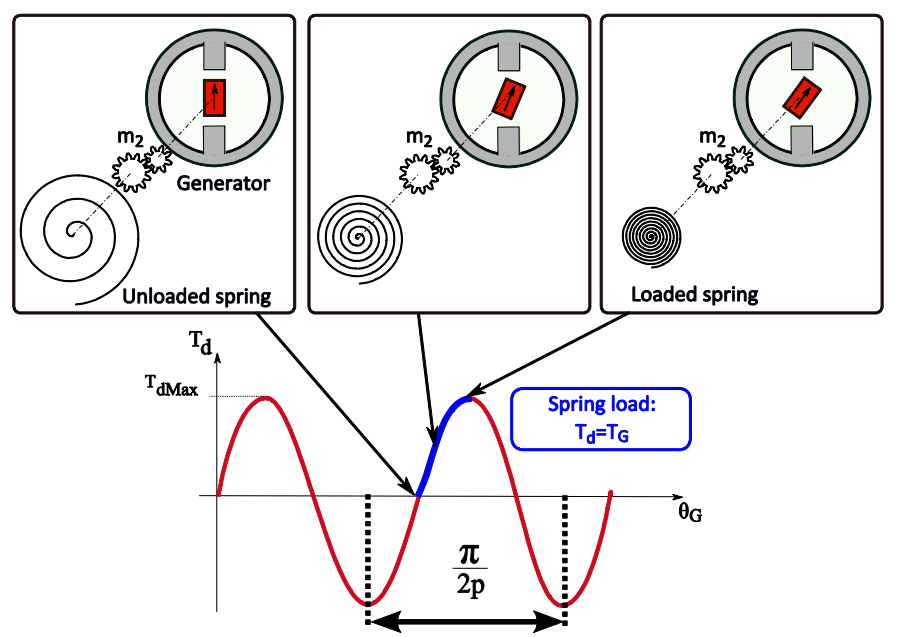

Fig. 5. Interaction betwenn detent torque and spring torque

This figure (Fig. 5), which depicts the generator structure, has obviously been simplified to more easily illustrate interactions between these two torques. In practice, the claw structure gives rise to a detent torque with strong asymmetry (i.e. two distinct amplitude maxima per period); this asymmetry could not be identified herein and we therefore did not take this specificity into account as part of the present study.

It was experimentally observed that the cumulative angular displacement $\theta_{\text {osc }}$ of the oscillating weight leading to spring discharge equaled $150^{\circ}$ or 2.6 radians, an observation that serves to identify the peak value of detent torque as:

$$
\mathrm{T}_{\mathrm{dMax}}=\frac{\mathrm{m}_{1} \mathrm{k}_{\mathrm{sp}} \theta_{\mathrm{osc}}}{\mathrm{m}_{2}}=10 \mu \mathrm{N} \cdot \mathrm{m}
$$

with $m_{1}$ being the gear ratio between weight and spring, $m_{2}$ the gear ratio between spring and generator, and $\mathrm{k}_{\mathrm{sp}}$ the spring stiffness of $12.5 \mu \mathrm{Nm} / \mathrm{rad}$. The detent torque value therefore 
determines the maximum energy stored in the spring for transmission to the generator during the discharge cycle, i.e.:

$$
\mathrm{W}_{\text {spring }}=\frac{1}{2} \mathrm{~m}_{2}^{2} \frac{\mathrm{T}_{\mathrm{dMax}}^{2}}{\mathrm{k}_{\mathrm{sp}}}=100 \mu \mathrm{J}
$$

The instantaneous electromagnetic torque is proportional to both the output current and permanent magnet flux $\Phi_{\mathrm{f}}$ derivative with respect to the rotor position $\theta_{\mathrm{G}}$ :

$$
\mathrm{T}_{\mathrm{em}}\left(\theta_{\mathrm{G}}\right)=\mathrm{I}_{\mathrm{G}} \frac{\mathrm{d} \Phi_{\mathrm{f}}}{\mathrm{d} \theta_{\mathrm{G}}}
$$

Furthermore, the torque due to friction originates from various sources: different types of mechanical friction, and magnetic losses due to eddy currents. For this research, the effects of dry friction due to mechanical friction and magnetic hysteresis losses could not be directly identified and have been neglected. A single component of equivalent viscous friction has been retained, denoted $\mathrm{T}_{\mathrm{f}}$ and identified from the following basic energy assessment. Since the maximum power potentially output by the generator is $10 \mathrm{~mW}$ at 5,000 rpm [8], i.e. a value corresponding to impedance matching (given that the limitations of this machine are not thermal), we have somewhat arbitrarily in a first time assumed a power loss due to viscous friction of approx. $30 \%$, which corresponds to a loss of $\mathrm{P}_{\mathrm{f}}=\mathrm{f}_{\mathrm{G}} \Omega_{\mathrm{G}}{ }^{2}=3 \mathrm{~mW}$ at the same speed. This assumption leads to a value of the viscous friction coefficient equal to $\mathrm{f}_{\mathrm{G}}=3 \cdot 10^{-9} \mathrm{Nm} / \mathrm{rad} / \mathrm{s}$.

The fundamental principle of dynamics applied to the generator rotor is thus expressed by:

$$
\mathrm{J}_{\mathrm{G}} \cdot \frac{\mathrm{d} \Omega_{\mathrm{G}}}{\mathrm{dt}}=\mathrm{T}_{\mathrm{G}}-\mathrm{T}_{\mathrm{d}}-\mathrm{T}_{\mathrm{em}}-\mathrm{T}_{\mathrm{f}}
$$

To better illustrate how this Autoquartz system operates during unwinding of the spring, Fig. 6 shows the block diagram of the entire system, where the active rectifier is loaded by a constant voltage source $\mathrm{V}_{\text {bus }}$, with $\mathrm{R}$ being the global resistance, i.e. the sum of the resistance of the generator armature and the resistances of semiconductor rectifiers.

The shape of the electromotive force $E_{G}$ during the discharge spring cycle, as obtained from a no-load simulation is shown in Fig. 7; it is similar to the shape measured by ETA [7]. We have not however been able to measure it experimentally due to a lack of direct access even after disconnecting the accumulator. Indeed, an internal capacitor remains in addition to consumption circuits that could not be disconnected.

The highly impulsive nature of the discharge spring (Fig.7), which lasts roughly $20 \mathrm{~ms}$, is observed each time the spring has stored a sufficient amount of energy.

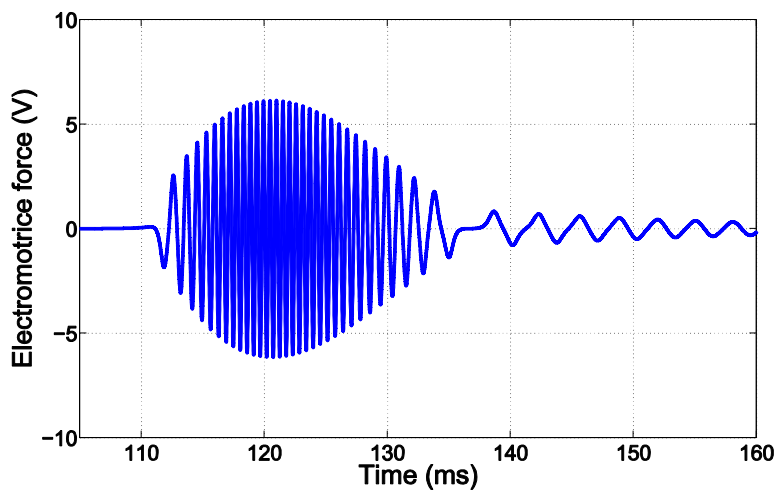

Fig. 7. Simulated waveform of the emf $E_{G}$

One purpose of this study has been to model the Autoquartz system connected to a storage element (lithium battery or supercapacitor, see Fig. 8). Since the storage element voltage inevitably fluctuates, depending on both the state of charge and instantaneous power, we evaluated the influence of voltage $\mathrm{V}_{\text {bus }}$, applied at the rectifier output, on energy recovered as the spring unwinds. This study was conducted experimentally: measure of current through a $10 \Omega$ shunt with an Agilent 6000 series oscilloscope. We also perform a simulation of system operation which allowed us, by comparing model-measurements, to identify a number of parameters.

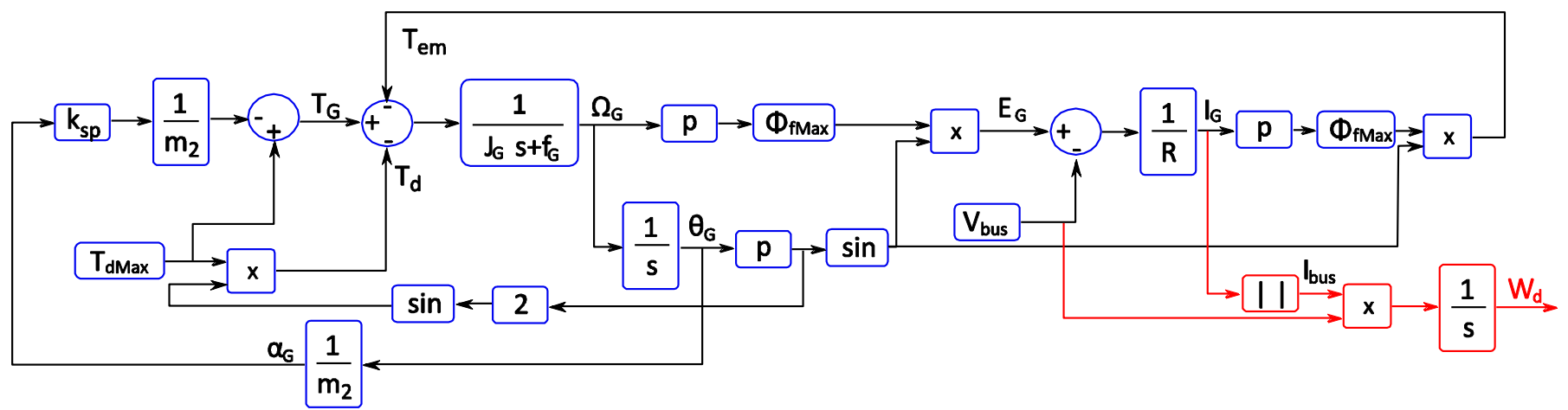

Fig. 6. Block diagram of the Autoquartz system during unwinding of the spring 


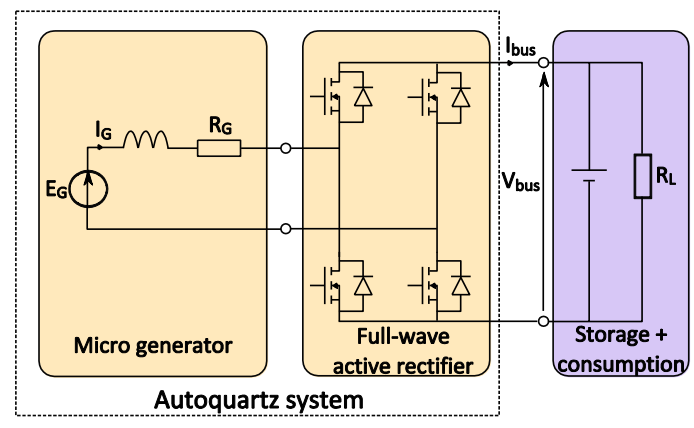

Fig. 8. : Diagram of the Autoquartz system connected to a voltage source (in this case, a storage element)

Since the active rectifier does not feature a reversible current, MOS transistors are only turned on when the microgenerator voltage exceeds the voltage $V_{\text {bus }}$ applied to Autoquartz system output. The current has a pulse shape with its frequency f proportional to $\Omega_{\mathrm{G}}$ (see Fig. 9). The measured speed $\Omega_{\mathrm{G}}$ and maximum current $\mathrm{I}_{\mathrm{M}}$, derived from experimental records (measurement period), make it possible to calculate the relationship between global resistance R (sum of the internal resistances of the generator and MOS transistors) and amplitude of the excitation flux $\Phi_{\mathrm{fMax}}$. Given the level of dispersion in the calculated parameter values, we averaged our results and identified a pair of parameters, i.e.: global resistance $\mathrm{R}=500 \Omega$, and excitation flux amplitude $\Phi_{\mathrm{fMax}}=0.51 \mathrm{mVs}$.
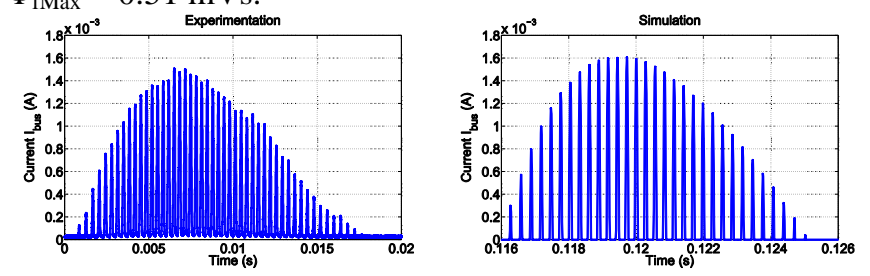

Fig. 9. Experimentation/simulation comparison of Autoquartz system output current with the system loaded by a voltage source $\mathrm{V}_{\text {bus }}=5 \mathrm{~V}$

From the values of experimentally identified parameters $\left(\mathrm{T}_{\mathrm{dMax}}=10 \mu \mathrm{Nm}, \Phi_{\mathrm{fMax}}=0.51 \mathrm{mVs}\right.$ and $\left.\mathrm{R}=500 \Omega\right)$ as well as those estimated from datasheets $\left(\mathrm{J}_{\mathrm{G}}=0.03 \mathrm{~g} \cdot \mathrm{mm}^{2}\right)$ or an energy assessment $\left(f_{G}=3 \cdot 10^{-9} \mathrm{Nm} / \mathrm{rad} / \mathrm{s}\right)$, we were able to compare experimental and simulated results (globalized) of the recovered energy within a discharge cycle $\mathrm{W}_{\mathrm{d}}$ as a function of voltage $\mathrm{V}_{\text {bus }}$ (Fig. 10).

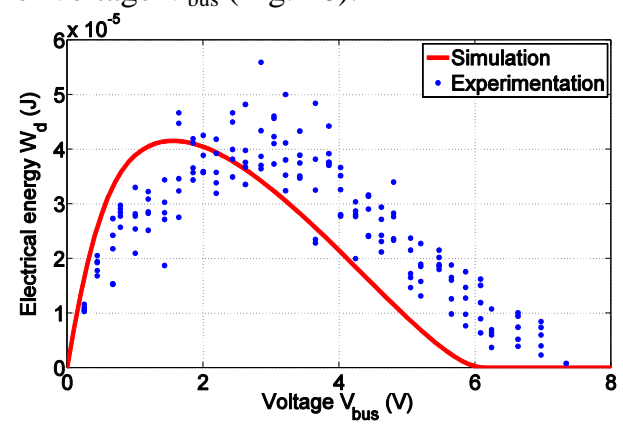

Fig. 10. Influence of voltage $\mathrm{V}_{\text {bus }}$ on the recovered energy of one discharge

Though some significant differences remain, the curve after simulation lies fairly close to the point cloud obtained from experimental measurements. The difference between these two results may be due to uncertainties on parameters given by the manufacturer as well as to estimated uncertainties; however, dispersion results must also be examined more closely (specifically early discharge occurring at variable values of detent torque due to high instability in the vicinity of the maximum). Obviously, it is possible to identify one or more sets of parameters capable of approximating the experimental results, but the preferred course of action, based on the initially known data, was to perform a sensitivity analysis focusing on various parameters.

Fig. 10 also reveals that the efficiency on cycle of one discharge depends on the value of voltage $\mathrm{V}_{\text {bus }}$ : this efficiency value reaches a maximum of about $40 \%$ for a voltage near $1.5 \mathrm{~V}$ in the simulation and $3 \mathrm{~V}$ under experimental conditions.

In order to better understand the possible origins of differences between simulations and experiments, we conducted a sensitivity analysis of simulations on the values of permanent magnet flux $\Phi_{\mathrm{fMax}}$ amplitude and detent torque $\mathrm{T}_{\mathrm{dMax}}$ amplitude (Fig. 11). These two parameters exert a direct influence on the waveform of the electromotive force $\mathrm{E}_{\mathrm{G}}$ (Fig. 7) and therefore on the curve shape of recovered energy from one discharge vs. continuous voltage $\mathrm{V}_{\text {bus }}$.
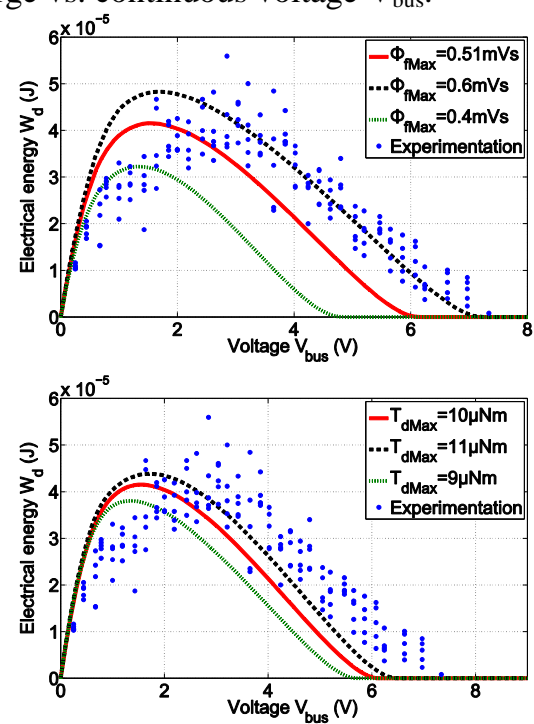

Fig. 11. Sensitivity analysis of the permanent magnet flux $\Phi_{\mathrm{fMax}}$ amplitude and the detent torque $\mathrm{T}_{\mathrm{dMax}}$ amplitude

The amplitude of the electromotive force is proportional to the excitation flux amplitude: the higher the amplitude, then (for the same voltage $\mathrm{V}_{\text {bus }}$ ) the higher the current and hence the greater the amount of recovered energy. The simulation results obtained clearly underscore such a trend. The increase in detent torque influences the energy stored in the spring; it can also be observed that as the value of $\mathrm{T}_{\mathrm{dMax}}$ rises, the amount of recovered energy increases, yet also note that the efficiency on cycle of one discharge becomes smaller. A closer look indicates that when the detent torque amplitude increases by $10 \%$, the energy stored by the spring increases by $21 \%$ (see (2)), but the maximum recovered energy on system output only increases by $5 \%$, i.e. a degraded efficiency on cycle. 


\section{ENERGY CONVERSION OPTIMIZATION}

We have been able to observe, through both the electromechanical model and experimentally, that in the case of load by a DC bus, an optimum voltage exists at the generator output for which the energy recovery of each spring discharge is maximized.

Two solutions allow maximizing energy recovery. The first one consists of adapting the winding by altering the number of turns $\mathrm{n}$ and the wire cross-section (so as to maximize filling of the coil window).

However, if it is not possible to influence generator construction or if the voltage varies excessively (for example by means of a supercapacitor), then a second solution for optimizing energy transfer might be to add a DC-DC converter between the Autoquartz system and the storage element, thus allowing for enslavement of voltage $V_{\text {bus }}$ at the Autoquartz system output.

Both solutions have been developed in [10].

\section{RESIZING THE INITIAL SYSTEM FOR A STUDY OF THE SCALE EFFECT ON ENERGY PRODUCTIVITY}

The aim of this study is to perform additional sizing in order to vary energy productivity. We re-optimize here some fundamental dimensional parameters that we have deliberately limited in number, while maintaining the overall architecture.

For each subsystem (containing an oscillating weight, spring, gear, generator, etc.), we have studied the impact of changes in the main parameters, with each taken separately from the complete system. We will thus analyse the influence of changes in these design parameters on the amount of recovered energy.

Remind that the recovered energy depends on the system parameters and on the movement imposed to the oscillating weight support which can be parameterized by 6 degrees of freedom. To simplify the following discussion, we considered a movement of excitation, similar to a walking motion, described in Figure 12. The simulation time is 10s, which is a good trade-off between a permanent regime establishment and a reasonable computation time.
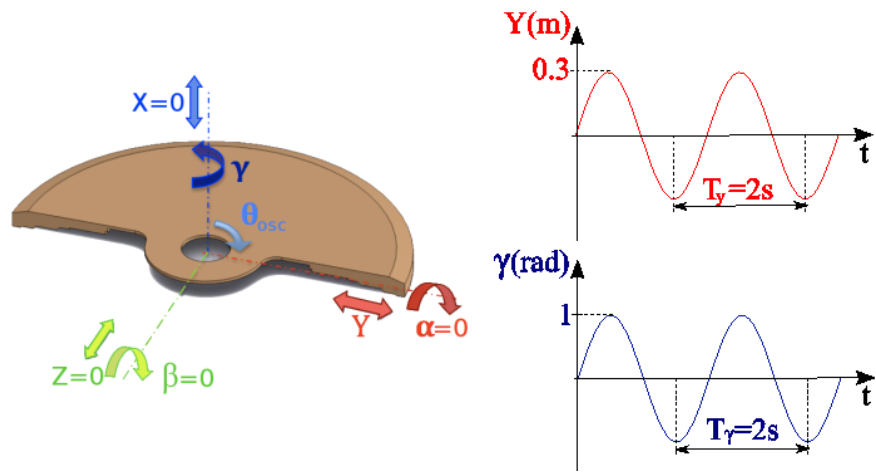

Fig. 12. Typical cycle movement imposed to the Autoquartz system
The selected normalized sizing parameters are five in number, these are:

- the scale factor th* ${ }_{\text {osc }}$ on the oscillating weight thickness,

- the factor $\mathrm{m}^{*}$ applied to the initial multiplication gear ratio $\mathrm{m}_{1}$ between oscillating weight and spring,

- $\quad$ the factor $\mathrm{k}_{\mathrm{sp}}$ applied to the initial spring stiffness $\mathrm{k}_{\mathrm{sp}}$,

- the factor $\mathrm{m}_{2}{ }_{2}$ applied to the initial multiplication gear ratio $m_{2}$ between spring and generator,

- the scale factor $\ell^{*}{ }_{\mathrm{G}}$ applied to all dimensions of the generator.

Fig. 13 shows a sketch of the energy conversion chain from the oscillating weight to the generator, with the above defined notations.

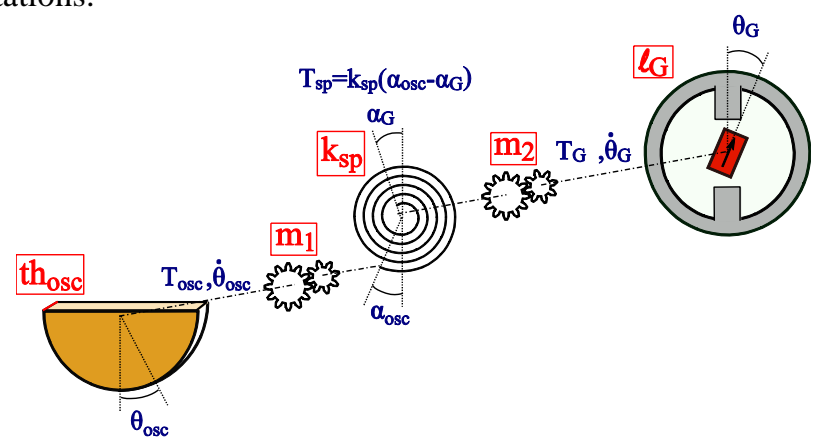

Fig. 13. Sizing parameters definitions of the Autoquartz system

Changing the parameters will first affect the energy stored in the spring and therefore, the recovered energy from one discharge $\mathrm{W}_{\mathrm{d}}$ (see (2)).

Furthermore, the sizing parameters modification causes a change in the discharge number $\mathrm{N}_{\mathrm{d}}$ per cycle. Remind that a discharge occurs when the spring torque $\mathrm{T}_{\mathrm{G}}$, transmitted on the rotor shaft of the generator through a multiplier gear with a ratio $\mathrm{m}_{2}$, becomes slightly higher than the peak value $T_{\mathrm{dMax}}$ of detent torque of the generator:

$$
\mathrm{T}_{\mathrm{G}} \geq \mathrm{T}_{\mathrm{dMax}} \Leftrightarrow \frac{\mathrm{k}_{\mathrm{sp}}}{\mathrm{m}_{2}} \mathrm{~m}_{1} \theta_{\text {osc }}-\alpha_{\mathrm{G}} \geq \mathrm{T}_{\mathrm{dMax}}
$$

The study of the influence of each sizing factor (taken separately) on the recovered energy on the typical cycle movement, denoted $\mathrm{W}_{\mathrm{t}}$, shows that there is always an optimal factor value for which the recovered energy on cycle is maximum. Strictly speaking, for each type of movement, as described in Fig. 12, it is possible to compute, using appropriate optimization approaches, the set of parameters (th $*_{\text {osc }}, \mathrm{m}^{*}{ }_{1}, \mathrm{k}_{\mathrm{sp}}^{*}, \mathrm{~m}^{*}{ }_{2}, \ell_{\mathrm{G}}$ ) maximizing $\mathrm{W}_{\mathrm{t}}$. However, we could not solve this complex optimization problem because of far too long simulation time. Therefore, we initially chose to optimize only the energy conversion chain constituted of oscillating weight, multiplier gear with a ratio $\mathrm{m}_{1}$ and spring, and thus to keep the multiplication ratio $\left(\mathrm{m}_{2}\right)$ and the generator geometry $\left(\ell_{\mathrm{G}}\right)$ as constants.

We therefore varied the scale factor th* ${ }_{\text {osc }}$ from 1 to 10 with a unit step, and for each value of th* ${ }_{\text {osc }}$, an exhaustive search 
is performed to find the couple of parameters $\left(\mathrm{m} *{ }_{1}, \mathrm{k} *{ }_{\mathrm{sp}}\right)$ maximizing the electrical energy on cycle $\mathrm{W}_{\mathrm{t}}$. For each $\left(\mathrm{m}^{*}{ }_{1}\right.$, $\mathrm{k}_{\mathrm{sp}}$ ), a first simulation is run to find the DC bus voltage $\mathrm{V}_{\text {bus }}$ that maximizes $\mathrm{W}_{\mathrm{d}}$ (see Fig.6), and then, a second simulation provide us $\mathrm{W}_{\mathrm{t}}$ (see Fig.3). Results are presented in Fig.14.

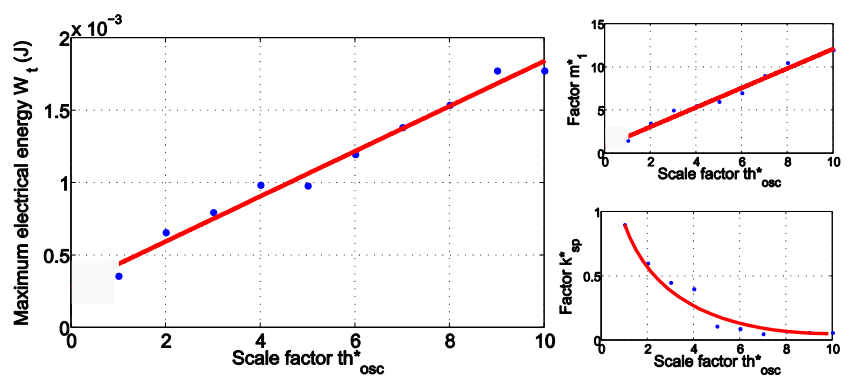

Fig. 14. Evolution of the maximum recovered energy on cycle $\mathrm{W}_{\mathrm{t}}$ according to the scale factor th* ${ }_{\mathrm{osc}}$, with the optimal couple of parameters $\left(\mathrm{m}^{*}{ }_{1}, \mathrm{k}_{\mathrm{sp}}\right)$

If the multiplication ratio $m_{1}$ between oscillating weight and spring, and the spring stiffness $\mathrm{k}_{\mathrm{sp}}$ are well sized, the optimal recovered energy on cycle $\mathrm{W}_{\mathrm{t}}$ increases linearly with the oscillating weight thickness th $\mathrm{osc}_{\text {. }}$. As the oscillating weight is proportional to the Autoquartz system volume, we therefore can observe that the recovered energy on cycle increases proportionally to the system volume.

In Fig. 14, we also can see that when the scale factor th* ${ }_{\text {osc }}$ increases, the multiplication ratio between oscillating weight and spring also increases. Indeed, when the size of the oscillating weight increases, the torque due to gravity effects become predominant, especially on that due to the effects of the spring through the multiplier gear with a ratio $\mathrm{m}_{1}$. Thus, in order not to approach a finite energy value only due to movements of the Autoquartz system support, the multiplication ratio between oscillating weight and spring should increase along with the oscillating weight thickness.

Besides, when the size of the oscillating weight increases, and therefore the optimal multiplication ratio $\mathrm{m}_{1}$, the optimal spring stiffness $\mathrm{k}_{\mathrm{sp}}$ decreases. Reducing the spring stiffness will actually lead to higher energy stored in the spring before discharge (see (2)), but also it will lead to a decrease in the number of discharge $\mathrm{N}_{\mathrm{d}}$ per cycle. However, this decrease is even less affected than the multiplication ratio $m_{1}$ increases (see (5)).

Finally, note that for a unit scale factor th* ${ }_{\text {osc }}$, the factors $\mathrm{m}^{*}{ }_{1}$ and $\mathrm{k}_{\mathrm{sp}}$ are not unitary, which means that the initial Autoquartz system could be better optimized for energy recovery.

\section{CONCLUSION}

This article has presented the energy analysis for an original micro-kinetic generator capable of generating electricity from movements of any kind, including very slow motions. This device, initially developed to supply energy to watches, had never, to our knowledge, undergone such an energy productivity study. Through the application of electromechanical modeling to various system components, combined with experimental data recordings, we have been able to identify individual model elements and reveal the existence of an optimum efficiency. Indeed, in the case of load by a DC bus, the applied bus voltage plays an important role in discharge cycle efficiency of the spring.

Finally, we conducted a parametric study that, for a given movement of the oscillating weight support, highlights the existence of an optimal set of parameters maximizing the recovered energy on cycle. Indeed, the modification of each parameter represents a trade-off between the electrical recovered energy from one discharge and the discharge number per cycle. Therefore, it is possible to study the influence of each parameter on the energy productivity and reoptimize the energy conversion chain while keeping the overall architecture. This parametric study is very complex and its study is not yet complete. We intend to first optimize the whole energy conversion chain, from the oscillating weight to the generator, but also, in a second time, take account of architectural changes such as, for example, the number of floors of the multiplier gears.

\section{ACKNOWLEDGMENT}

The authors would like to thank Yves Guérin, Development Engineer at ETA SA (Grenchen, Switzerland), for the information he kindly provided on the Autoquartz system. Thanks are also addressed to the ST2I CNRS Department, which helped finance this project through a PEPS grant.

\section{REFERENCES}

[1] M. Lossec, "Study and realization of a multi-sources energy generator by harvesting human environment resources" (in French), Master's degree internship, SEGE Nantes, SATIE, July 2008, Available: http://e-mecatronique.bretagne.ens-cachan.fr/file.php/35/ DocPedagogiques/MarianneLOSSEC_M2R_Juillet08.pdf

[2] M. Lossec, B. Multon, H. Ben Ahmed, L. L'Hours, P. Quinton, G. Nicolas, A. Sorel, J. Prioux, "Optimization Methodology for a MultiSource-Energy Generation System using the Human Environment Energy Resource”, in NEST 2009 (New Energy Solutions in Tours), May 2009.

[3] K. Reimann, "Energy considerations for small electromachanical generators that use human body motion", Technical Note Philips Research Eindhoven, May 2005

[4] D.P. Arnold, "Review of microscale magnetic power generation", IEEE Transaction on magnetics, vol 43, No. 11, November 2007.

[5] J. Wang, W. Wang, G.W. Jewell, D. Howe, "Design of a miniature permanent-magnet generator and energy storage system", IEEE Transaction on industrial electronics, vol 52, No. 5, October 2005.

[6] Gilomen, P. Scmidli, ETA SA, Granges, Suisse, " Quartz movement lady ( 8 3/4"') whose energy is supplied by a generator, Caliber ETA 204.911" (in French), in 8e Congrès européen de Chronométrie Genève - September 2000

[7] B. Guilomen, J.L. Beguin, R. Bugmann, ETA SA, Granges, Suisse, "Quartz movement whose energy is supplied by a generator, Caliber ETA 205.111" (in French), in La montre automatique - de la mécanique à l'électronique, 5e Journée d'Etude - Vallée de Joux, Le Sentier - October 1997

[8] Kinetron, The Micro Energy Company, "The Micro Generating System for a Watch", Available: http://www.kinetron.nl/cms/publish/content/ downloaddocument.asp?document_id=9

[9] Kinetron, The Micro Energy Company, "The 14-pole Micro Generator with Sm2Co17 magnet (MG205)", Available: http://www.kinetron.nl/ $\mathrm{cms} /$ publish/content/downloaddocument.asp?document_id=7

[10] M. Lossec, B. Multon, H. Ben Ahmed, C. Fredy, F. Le Bourhis, S. Moya "Study of a micro-kinetic generator: modelization and optimization of energy conversion" (in French), in Proc. Electrotechnique du futur, Compiegne, France, September 2009 